\title{
Correlation between Child Abuse and School Refusal among Primary School Children in Benha City
}

\author{
Amira Mostafa Abdel-Hameed ${ }^{1}$, Maaly Ibrahim EL-Malkey ${ }^{2}$ and Mona Mohamed Barakat ${ }^{3}$
}

(1)Nursing specialist at Shebin El- kom Teaching Hospital (2)Professor of Psychiatric and Mental Health Nursing, Faculty of Nursing - Menofia University (3)Assistant professor of Psychiatric and Mental Health Nursing, Faculty of Nursing - Benha University

\section{Abstract:}

Child abuse is a serious problem that results in devastating and long lasting damage to individual and community at large. Child abuse is a global issue affects children of all ages, gender, races, and ethnicities and in varied socio economic classes linked to causes of child morbidity, mortality, school refusal and educational dropout. Aim of the study: This study aimed to identify the correlation between child abuse and school refusal among primary school children in Benha City, Qaliubya Governorate. Sample: The study sample consisted of 400 students from 5th and 6th grade of education from Alshahid Abdal-Monem Riad School. Research Design: A descriptive correlational design was utilized in this study. Tools: In this study two tools were used for data collection: I) a structured interviewing questionnaire included socio-demographic data of the studied students and their parents as well as questionnaire about different types of child abuse. II) School Refusal Assessment Scale. Results: The results revealed that, near to half of the studied children have moderate level of child abuse from their family, near to half have high level of child abuse from school and less than half of them have mild level of school refusal behavior. Also, there was a highly statistically positive correlation between total child abuse and total school refusal scales among primary school children in Benha city. Conclusion: The study concluded that studied children exposed to child abuse from family, school, have exposed to mild level of school refusal and there was a highly statistically positive correlation between total child abuse and total school refusal scales among primary school children in Benha city. Recommendations: Therapeutic guidance programs should be prepared for children who exposed to child abuse or have school refusal. Psycho-educational programs should be integrated as nursing intervention for students and their parents to enhance their psychological wellbeing as well as reducing school refusal .

Key words: Child abuse, Children, School refusal

\section{Introduction}

School age is the segment of the life span that extended from age 6 years to approximately 12 years. School age is the last period in which girls and boys are close in size and body proportions while their social and developmental growth accelerates and increase in complexity (Mcleod, 2018). Child abuse is a serious problem that results in devastating and long lasting damage to individual and community at large. The
World Health Organization WHO, (2017) defines child abuse and child maltreatment as "all forms of physical and/or emotional illtreatment, sexual abuse, neglect or negligent treatment or commercial or other exploitation, resulting in actual or potential harm to the child's health, survival, development or dignity in the context of a relationship of responsibility and trust or power. Experiencing abuse can impact on a child's development and behavior. The negative 
impact of child maltreatment on the child, family, and society as a whole cannot be underestimated. Abused child suffer both immediate and long-term impairments to their mental, emotional, physical, educational, and social well-being (Jordan, et al., 2016).

There is a number of risk factor that may or may not be direct causes of child abuse. A combination of risk factors are those characteristics linked with child abuse and neglect include individual, relational, community, and societal factors contribute to the risk of child abuse and neglect. Although children are not responsible for the harm inflicted upon them, certain characteristics have been found to increase their risk of being abused and or neglected as being child with special needs that may increase caregiver burden (e.g., disabilities, mental health issues, and chronic physical illnesses (National Center for Injury Prevention and Control, 2019).

School refusal is a serious emotional problem that is stressful for both children and parents that is characterized by an emotional distress at a time of attending school or school attendance difficulties. It can result in significant short- and long-term effects on the social, emotional, and academic development of the child due to abuse. School refusal can take many forms. It can include behaviors like frequently struggling to arrive at school on time, leaving before the school day ends, or not attending school at all. Headaches, fatigue, stomachaches, and other physical symptoms of anxiety may make it hard to get off to school in the morning or make it feel necessary to leave early (Maynard et al., 2015).

The role of nurses can be involved in prevention, early identification, reporting, and treatment related to child maltreatment to prevent school refusal because of their opportunity to interact with children daily. School nurses are professionally and ethically accountable to do the following: know local laws, regulations, policies, and procedures for reporting child maltreatment, know the signs and potential indicators of child maltreatment, provide clear nursing documentation that includes questions asked and answers given and use a body diagram when appropriate for suspected child maltreatment (National Association of School Nurses, 2016).

\section{Significance of the study}

Child abuse is a global issue affects children of all ages , gender, races, ethnicities, in varied socio economic classes and is in the forefront in the line of wide spread social issues and social problems (Diagneault et al., 2013). Every year about 41,000 children under 15 years are victims of homicide. Child abuse has serious consequences, the effects can be immediate as serious injuries, die or last as life time in which adults who were abused or neglected as children have a higher risk of perpetrating or being a victim of violence, depression, obesity, high-risk sexual behaviors and unintended pregnancies .Studies show that child abuse has high economic costs in medical expenses, legal costs, and lost productivity (WHO, 2017). In our Egyptian society children represent abroad sector of the population, healthy childhood is the cornerstone of any dynamic and healthy society so this study will be conducted to determine the correlation between child abuse and school refusal among primary school children in Benha city.

\section{Aim of the study:}

This study aims to identify the correlation between child abuse and school refusal among primary school children in Benha city. 


\section{Research questions:}

What is the level of child abuse and school refusal among primary school children in Benha City?

What is the correlation between child abuse and school refusal among primary school children in Benha city?

\section{Subject and Method: \\ Research design:}

A descriptive correlational design was used to carry out the present study .

\section{Research setting:}

The present study was conducted in Alshahid Abdal-monem Riad School in Benha City, Qaliubiya Governorate, which is affiliated to the ministry of education (after using simple random to choose this school). The capacity of the Alshahid Abdal-monem Riad School is 1029 students. Additionally, the flow rate of student is 200 pupils annually.

\section{Research Sampling:}

Sample size: The sample size was calculated at power $80 \%$, confidence level $95 \%$ and margin of error 5\%. It was 400 students that represent $100 \%$ according to sensitive test of total students who studied in the primary school (Alshahid Abdal-monem Riad) in Benha city in 2019. The target population was 400 students.

Sample technique: The researcher used a convenient sample of (400) students from Alshahid Abdal-monem Riad School in Benha City who fulfilled the following criteria.

All available students were in primary school in the selected classes from 5th and 6th grade of education during data collection.

Both sexes .

Agreed to participate in the study.
Free from psychiatric disorders.

\section{Tools for data collection:}

In order to fulfill the aim of the study the data were collected using the following tools :

\section{Tool (I): A structured Interviewing Questionnaire:}

This questionnaire was developed by the investigator after reviewing the related literature to obtain complete data about the students. This questionnaire was covered the following items-:

\section{Part I: Socio-demographic Data :}

It consists of 14 items to elicit data about the socio demographic characteristics of studied students and their parents include:

Socio-demographic characteristics of the child's parents include mother's age, marital status, mother's educational level, mother's occupation, father's age, father's educational level, father's occupation and residence.

Socio-demographic characteristics of the child include age, gender, number of siblings, order of the child among his siblings, cohabitation and classroom.

\section{Part II: Child Abuse Questionnaire:}

This questionnaire was developed by ElNagar, (1998) and modified by the researcher to measure child abuse from child's family (father, mother, siblings) and school. This tool consists of 100 questions; it was in the form of a Likert scale with three levels; (2) always, (1) sometimes and (0) never. It was divided into 4 portions, as the following-:

-Questionnaire 1 about physical abuse: It included 19 questions concerned with child physical abuse from mother, father or siblings 
at home and 11 questions concerned with child physical abuse at school .

-Questionnaire 2 about sexual abuse: It included 13 specific questions related to sexual behavior from mother, father or siblings at home and 5 specific questions related to sexual behavior at school as watching sexual films and pictures

- Questionnaire 3 about emotional abuse: It included 19 questions concerned with child emotional abuse from mother, father or siblings at home and 12 questions concerned with child emotional abuse at school as threatening, criticism, verbal abuse and the negative outcomes of emotional abuse as isolation

-Questionnaire 4 about neglect: It included 19 questions concerned with parent and school neglect for the child from mother, father or siblings at home and 2 questions at school.

\section{Scoring system:}

$>50 \%$ indicates mild child abuse.

$50<75 \%$ indicates moderate child abuse.

$<75 \%$ indicates severe child abuse.

\section{Tool (II): School Refusal Assessment Scale}

- Revised (SRAS-R:(

This scale was developed by Kearney, (2002).This scale was used to assess which functions are most relevant to a particular case of school refusal behavior. This scale consists of (24 questions) in the form of a Likert scale with three levels; (2) always, (1) sometimes and (0) never. It consists of four function or subscales related to school refusal behavior 6 questions for each function or subscale. Function one (avoidance or stimuli provoking negative affectivity), it includes items 1, 5, 9, 13, 17 and 21. Function two (escape from aversive social and/or evaluative situations), it includes items 2, 6, 10, 14, 18 and 22. Function three (attention seeking), it includes items 3, 7, 11, 15, 19 and $23 \&$ function four (tangible rewards), it includes items 4, 8, 12, 16, 20 and 24

\section{Scoring system:}

$>25 \%$ indicates no school refusal behavior. $25<50 \%$ indicates mild school refusal.

$50<75 \%$ indicates moderate school refusal $<75 \%$ indicates severe school refusal.

\section{Administrative approval :}

A written letter was issued from the Dean of the Faculty of Nursing, Benha University and submitted to the director of Alshahid AbdalMonem Riad School after obtaining an official letter from security which is affiliated to the ministry of education. An official permission was obtained to carry out the study from the directors of the above mentioned setting. The objectives and the nature of the study were explained to the administrative personnel and then it was possible to carry out the study with minimum resistance.

\section{Validity and reliability of tools-:}

The researcher conducted an extensive literature review and developed the questionnaire from previously used tools and reviewing pertinent review for validity purposes. The questionnaire was formulated and was crossed-checked for its content validity by five qualified experts in psychiatric and community health nursing departments who reviewed the tools for content accuracy and internal validity. Suggestions were incorporated into the instrument. Test - retest reliability was applied by the researcher for testing the internal consistency of the instrument. Test retest reliability of school refusal assessment scale was .86 for total scale and $(.87, .88, .88$ 
and .85) for four subscales (avoidance or stimuli provoking negative affectivity, escape from aversive social and/or evaluative situations, attention seeking, and tangible rewards) respectively. Also, test - retest reliability of child abuse questionnaire was 0.92 .

\section{Ethical considerations:}

Approaches to ensure the ethical issues were considered in the study regarding confidentiality and informed consent. Confidentiality was achieved by the use of locked sheets without names of the participants and replaced by numbers. All the participants were informed that the information they provided during the study would be kept confidential and used only for statistical purpose and after finishing the study. Each student was informed that participation in the study was voluntary, and had the right to withdraw from the study at any time.

\section{Pilot study:}

A pilot study conducted to test the applicability of the instruments, the feasibility of the study and estimate the time needed for collecting the data. It was conducted on $10 \%$ of the total sample (40 students) according to the selection criteria. All students participated in the pilot study excluded from the study sample because the researcher rephrased some questions and sentences then set the final fieldwork schedule.

\section{Actual study}

The researcher introduced herself to the students then explained the aim of the study to every one of them and the type of questionnaire required to fill was given to each participant.
The tools of the study were distributed between the students who met the inclusion criteria and accepted participating in the study and they were asked to fill them individually

A small group interview was done in the classroom of school. The researcher faced the students and asked questions in Arabic and they recorded their answers in the questionnaire paper.

Each 5 student was interviewed to collect the data related to socio-demographic data, child abuse questionnaire, as well as school refusal assessment scale. Questionnaire distributed to students daily from 8.30a.m to 1.30 p.m except the vocation .

Each student was handed the questionnaire and answered it under observation of the researcher. A student who can't read well, the researcher helps them to record their answers .

The researcher interviewed about 50-55 student a day.

The first instrument (child abuse questionnaire) was filled in about 15-20 minutes and the second instrument (school assessment scale questionnaire) was filled in about 5- 10 minutes.

The process of data collection occurred daily and took about one month except the vocation (Friday and Saturday), started in 28 November 2019 and ended in 18 December 2019 .

\section{Statistical analysis \\ Data analysis}

Upon completion of data collection, the collected data were organized, tabulated; statistically analyzed by using an IBM personal computer with Statistical Package of Social Science (SPSS) version 22. Data were presented using descriptive statistics in form 
of number and percentage, mean, standard division, and Qualitative variables were comparing using the chi- square test. For quantitative data, person correlation coefficient ( $r$ ) was used for correlation analysis and degree of significance was identified. A statistically significant difference was considered if $\mathrm{p}$-value was $<$ 0.05. A highly statistically significant difference was considered if $\mathrm{p}$-value was $<$ 0.001 .

\section{Results}

Table (1) reveals that, more than three quarters of the studied children $(79.0 \%)$ their age ranging from $10-12$ years, and about half $(51.3 \%)$ were female. Also, regarding to number of siblings, more than one third $(40.3 \%)$ had three siblings and about one third (33.3\%) of children were the third child among his siblings. The table shows also, the majority $(93.8 \%)$ of the studied children were living with their family (father \& mother) and more than half $(51.8 \%)$ were in fifth grade.

Table (2) illustrates that there was no statistical significant difference between level of different form of abuse and different family members .

Figure (1) illustrates that less than half of the studied children $(48.0 \%)$ have moderate level of abuse from their family.

Table (3) refers that less than half of the studied children $(48.5 \%)$ had a high level of neglect. Also, the table shows that, the majority of the studied children $(85.7 \%)$ had low level of sexual abuse from school .
Figure 2 illustrates that less than half of the studied children $(46.8 \%)$ had high level of child abuse from school .

Figure 3 illustrates that less than half of the studied children $(41.3 \%)$ had mild level of school refusal.

Table (4) demonstrates that the majority of the studied children (90.0\%) reported high level of "escape from aversive social and/or evaluative situations". Also, the same table shows that more than half $(59.0 \%)$ of the studied children reported a high level of "avoidance or stimuli provoking negative affectivity ."

Table (5) indicates that there was statistically significant negative correlation between total family abuse subscale and total school refusal with $\mathrm{P}$ value $<(0.05)$. While there was a highly statistically positive correlation between total school abuse subscale and total school refusal with $\mathrm{P}$ value $=(0.001)$.

Table (6) demonstrates that there was no statistically significant correlation between total school refusal subscale and total child abuse with $\mathrm{P}$ value $>0.05$, while, there was a highly statistically positive correlation between total child abuse and total school refusal with $\mathrm{P}$ value $<(0.001)$. 
Table (1): Distribution of studied children regarding to their socio-demographic characteristics $(n=400)$.

\begin{tabular}{|c|c|c|}
\hline \multirow[b]{2}{*}{ Socio-demographic characteristics of child } & \multicolumn{2}{|c|}{ The studied children $(n=400)$} \\
\hline & No & $\%$ \\
\hline \multicolumn{3}{|l|}{ Age (years) : } \\
\hline - 10 - 12 years & 316 & 79.0 \\
\hline - $12 \geq$ years & 84 & 21.0 \\
\hline \multicolumn{3}{|l|}{ Gender: } \\
\hline - Male & 205 & 51.3 \\
\hline - $\quad$ Female & 195 & 48.8 \\
\hline \multicolumn{3}{|l|}{ Number of siblings: } \\
\hline - One & 38 & 9.5 \\
\hline - $\quad$ Two & 105 & 26.3 \\
\hline - $\quad$ Three & 161 & 40.3 \\
\hline - Four or More & 96 & 24.0 \\
\hline \multicolumn{3}{|l|}{ The order of child among his siblings: } \\
\hline - $\quad$ The first & 113 & 28.3 \\
\hline - $\quad$ The second & 94 & 23.5 \\
\hline - $\quad$ The third & 133 & 33.3 \\
\hline - $\quad$ The fourth & 24 & 6.0 \\
\hline - $\quad$ The last & 36 & 9.0 \\
\hline \multicolumn{3}{|l|}{ Cohabitation: } \\
\hline - $\quad$ Father & 13 & 3.3 \\
\hline - $\quad$ Mother & 6 & 1.5 \\
\hline - $\quad$ Father and mother & 375 & 93.8 \\
\hline - Other & 6 & 1.5 \\
\hline \multicolumn{3}{|l|}{ Classroom: } \\
\hline - $\quad$ Fifth grade & 207 & 51.8 \\
\hline - $\quad$ Sixth grade & 193 & 48.3 \\
\hline
\end{tabular}

Table (2): Relationship between total level of different forms of child abuse and different family members $(n=400)$.

\begin{tabular}{|c|c|c|c|c|c|c|c|c|c|c|}
\hline \multirow{2}{*}{ Types of child abuse } & \multicolumn{2}{|c|}{ Mother } & \multicolumn{2}{|c|}{ Father } & \multicolumn{2}{|c|}{ Siblings } & \multicolumn{2}{|c|}{ Total } & \multirow{2}{*}{$\mathbf{X}^{2}$} & \multirow{2}{*}{ p-value } \\
\hline & No & $\%$ & No & $\%$ & No & $\%$ & No & $\%$ & & \\
\hline \multicolumn{11}{|l|}{ Physical abuse } \\
\hline High & 178 & 44.4 & 176 & 44.0 & 176 & 44.0 & 177 & 44.2 & \multirow{3}{*}{0.42} & \multirow{3}{*}{0.98} \\
\hline Moderate & 171 & 42.8 & 178 & 44.5 & 176 & 44.0 & 175 & 43.8 & & \\
\hline Low & 51 & 12.8 & 46 & 11.5 & 48 & 12.0 & 48 & 12.0 & & \\
\hline \multicolumn{11}{|l|}{ Emotional abuse } \\
\hline High & 180 & 45.0 & 174 & 43.5 & 174 & 43.5 & 176 & 44.0 & \multirow{3}{*}{2.35} & \multirow{3}{*}{0.63} \\
\hline Moderate & 167 & 41.8 & 183 & 45.8 & 183 & 45.8 & 178 & 44.4 & & \\
\hline Low & 53 & 13.2 & 43 & 10.7 & 43 & 10.7 & 46 & 11.6 & & \\
\hline \multicolumn{11}{|l|}{ Neglect } \\
\hline High & 178 & 44.5 & 173 & 43.3 & 172 & 43.0 & 174 & 43.6 & \multirow{3}{*}{0.46} & \multirow{3}{*}{0.97} \\
\hline Moderate & 179 & 44.8 & 181 & 45.3 & 186 & 46.5 & 182 & 45.5 & & \\
\hline Low & 43 & 10.7 & 46 & 11.4 & 42 & 10.5 & 44 & 10.9 & & \\
\hline \multicolumn{11}{|l|}{ Sexual abuse } \\
\hline High & 7 & 1.8 & 5 & 1.3 & 5 & 1.3 & 6 & 1.4 & \multirow{3}{*}{1.13} & \multirow{3}{*}{0.88} \\
\hline Moderate & 7 & 1.8 & 10 & 2.5 & 10 & 2.5 & 9 & 2.3 & & \\
\hline Low & 386 & 96.4 & 385 & 96.2 & 385 & 96.2 & 385 & 96.3 & & \\
\hline
\end{tabular}




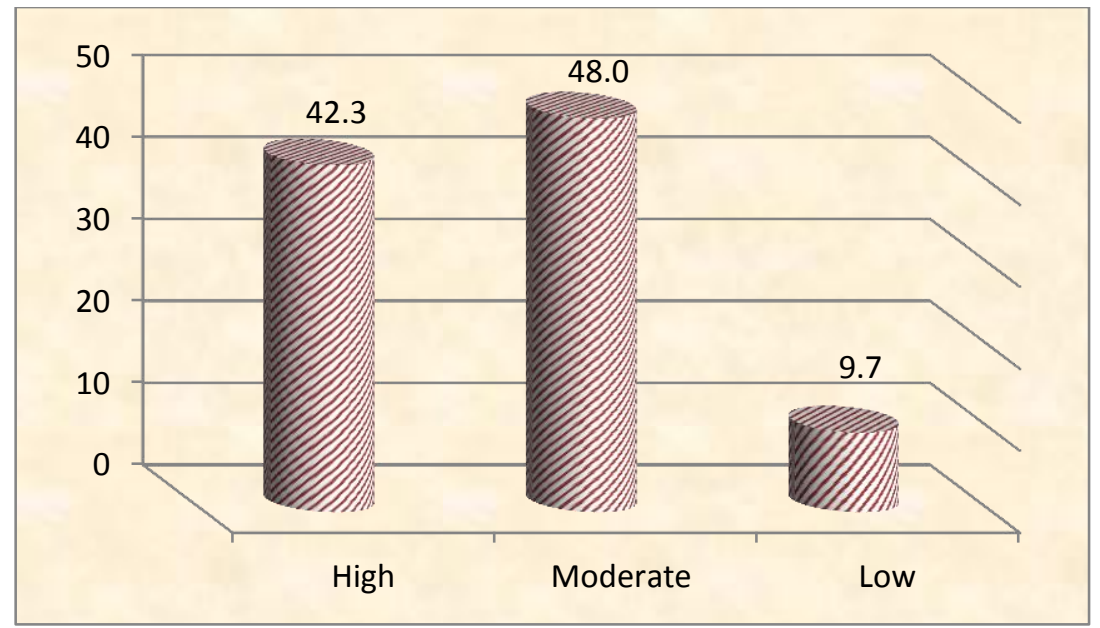

Figure (1): Distribution of studied children regarding to total level of abuse from their family $(n=400)$.

Table (3): Distribution of the studied children regarding to level of child abuse from school.

\begin{tabular}{|l|c|c|c|c|c|c|}
\hline \multirow{2}{*}{ Types of child abuse } & \multicolumn{2}{|c|}{ High } & \multicolumn{2}{c|}{ Moderate } & \multicolumn{2}{c|}{ Low } \\
\cline { 2 - 6 } & No & \% & No & \% & No & \% \\
\hline Physical abuse & 184 & 46.0 & 148 & 37.0 & 68 & 17.0 \\
\hline Emotional abuse & 182 & 45.5 & 153 & 38.3 & 65 & 16.3 \\
\hline Neglect & 194 & 48.5 & 138 & 34.5 & 68 & 17.0 \\
\hline Sexual abuse & 20 & 5.0 & 37 & 9.3 & 343 & 85.7 \\
\hline
\end{tabular}

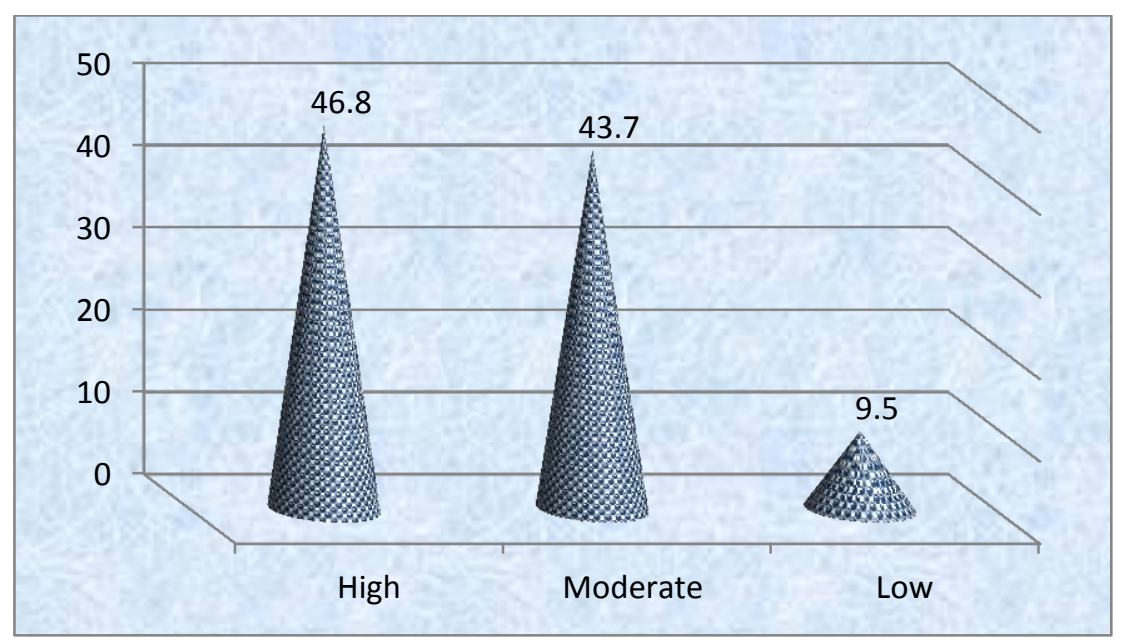

Figure (2): The total level of school abuse among the studied children $(n=400)$. 


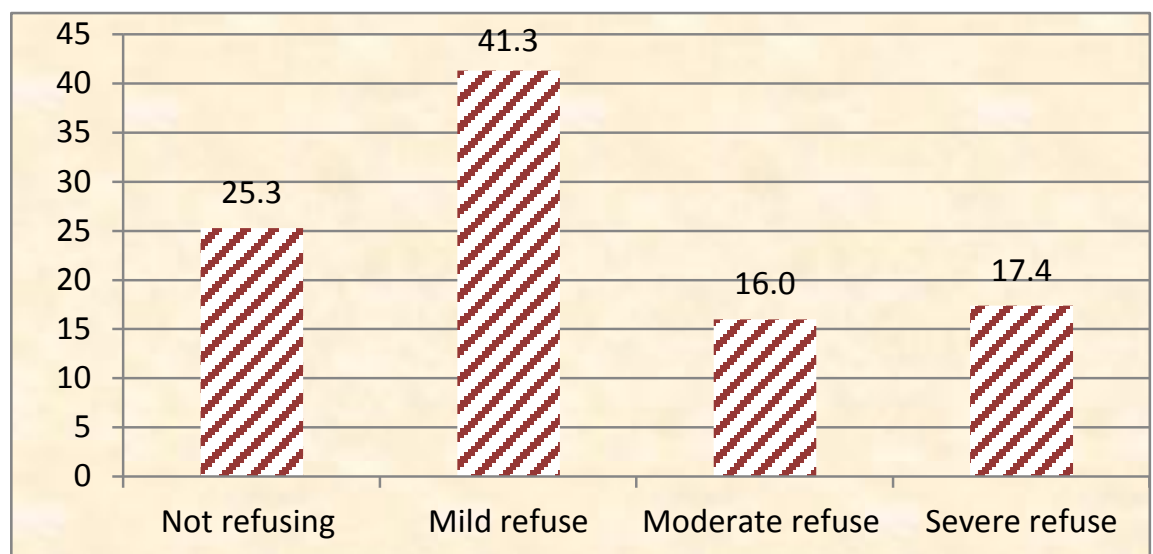

Figure (3): Distribution of studied children regarding to level of school refusal $(n=400)$.

Table (4): Distribution of the studied children regarding to total level of school refusal subscale $(n=400)$.

\begin{tabular}{|c|c|c|c|c|c|c|}
\hline \multirow[t]{2}{*}{ Total school refusal subscale } & \multicolumn{2}{|c|}{ Mild } & \multicolumn{2}{|c|}{ Moderate } & \multicolumn{2}{|c|}{ Sever } \\
\hline & No & $\%$ & No & $\%$ & No & $\%$ \\
\hline $\begin{array}{l}\text { Function one (avoidance or stimuli provoking negative } \\
\text { affectivity) items } 1,5,9,13,17 \text { and } 21 \text {. }\end{array}$ & 38 & 9.4 & 127 & 31.6 & 236 & 59.0 \\
\hline $\begin{array}{l}\text { Function two (escape from aversive social and/or } \\
\text { evaluative situations) items } 2,6,10,14,18 \text { and } 22 \text {. }\end{array}$ & 10 & 2.5 & 30 & 7.5 & 360 & 90.0 \\
\hline $\begin{array}{l}\text { Function three (attention seeking) items } 3,7,11,15,19 \\
\text { and } 23 \text {. }\end{array}$ & 66 & 16.5 & 174 & 43.5 & 161 & 40.0 \\
\hline $\begin{array}{l}\text { Function four (tangible rewards) items } 4,8,12,16,20 \text { and } \\
24 \text {. }\end{array}$ & 77 & 19.3 & 181 & 45.3 & 142 & 35.4 \\
\hline
\end{tabular}

Table (5): Correlation between total school refusal and total child abuse subscales among the studied children $(n=400)$.

\begin{tabular}{|l|c|c|}
\hline \multirow{2}{*}{ Child Abuse Subscales } & \multicolumn{2}{|c|}{ Total school refusal } \\
\cline { 2 - 3 } & $\mathrm{R}$ & $\mathrm{p}$-value \\
\hline Family abuse subscale & -0.42 & $0.021^{*}$ \\
\hline School abuse subscale & 0.72 & $0.000^{* *}$ \\
\hline
\end{tabular}

$*_{\text {when }} \mathrm{p}<0.05$ there was statistically significant differences.

$* *$ when $\mathrm{p}<0.001$ there was highly statistically significant differences.

Table (6): Correlation between child abuse and total school refusal subscale among the studied children $(n=400)$.

\begin{tabular}{|l|c|c|}
\hline \multicolumn{1}{|c|}{ School refusal scales } & \multicolumn{2}{c|}{ Total child abuse } \\
\cline { 2 - 3 } & $\mathrm{r}$ & $\mathrm{p}$-value \\
\hline Function one (avoidance or stimuli provoking negative affectivity). & 0.07 & 0.12 \\
\hline $\begin{array}{l}\text { Function two (escape from aversive social and/or evaluative } \\
\text { situations). }\end{array}$ & 0.02 & 0.55 \\
\hline Function three (attention seeking). & 0.08 & 0.07 \\
\hline Function four (tangible rewards). & 0.08 & 0.08 \\
\hline Total school refusal & 0.91 & $0.000^{* *}$ \\
\hline
\end{tabular}

When $\mathrm{p}>0.05$ there was no statistically significant differences.

$* *$ when $\mathrm{p}<0.001$ there was highly statistically significant differences. 


\section{Discussion}

Child abuse is major threats to child health and well-being. WHO, (2019) recognized that child abuse is a major international health problem with unacceptable levels of morbidity and mortality. Child abuse is a serious problem that results in devastating and long lasting damage to individual and community at large, and can destroy child self-concept, self- esteem, relationships, ability to trust and leading causes of child morbidity and mortality (Gilbert et al., 2015).

Regarding to socio-demographic characteristics of the studied children, the current study result shows that the majority of studied students' age were ranging from $10-$ 12 year. From the researcher point of view, this is due to conducting a research on the fifth and sixth grade of students and they enter school at age of six or seven. This finding was similar to the study done by Nearchou, (2018) who reported that the majority of the studied students' age ranging from $10-12$ year. On the other hand, Gutuza \& Mapolisa, (2015) reported that more than one third of the studied participants' age was ranging from $10-12$ year.

Concerning to child's gender, the current study result reveals that more than half were male. From the researcher point of view, it may due to number of male in this year was more than female. This finding was similar to the study done by Mohamed et al., (2016); \& Saddik and Hattab, (2012) who reported that more than half of the studied students were male. On the other hand, these findings were in disagreement with a study carried out by Panel-Grace et al., (2018) who revealed that less than half of the studied students were male.

Concerning to the number of siblings, the current study result illustrates that less than half of the studied students were three. From the researcher point of view of, this may be due to low level of awareness about family planning and most of Egyptian families like children. This finding was similar to the study done by Abd El Aziz et al., (2017) who reported that less than half of the studied students were three or more. On the other hand, these findings were in disagreement with a study carried out by Nguyen et al., (2009) who revealed that less than one third were three or more.

Concerning to birth order, the current study revealed that about one third of the studied participants were the third child. These findings were in agreement with a study carried out by Abd El Aziz et al., (2017) who revealed that about one third of the studied participants were the third child. These findings were in disagreement with a study carried out by Matar, (2014) who showed that less than half of the studied participants were third child.

Concerning to cohabitation, the current study showed that the majority of the studied students were lived with their family. From the researcher point of view, it may due to presence of moral values and ethics and following social habits among people in Egyptian community to have stable families. This finding was similar to the study done by Şahbal et al., (2016); \& Saddik \& Hattab, (2012) who reported that the majority of the studied students were lived with their family. On the other hand, this result was in disagreement with, Ribeiro, (2015) who reported that less than half of children lived with their parents

Regarding to prevalence of child abuse among the studied children, the current study revealed that, less than half of the studied children reported physical abuse, followed by emotional abuse, neglect then sexual abuse. From the researcher point of view, it is a common sense that parents use physical punishment and threatening together, these results agreed with Christoffersen, (2013) \& Akmatov, (2011) who revealed that less than half of the studied children exposed to physical abuse, followed by emotional abuse, neglect then sexual abuse.

On the other hand, Mogaddam et al., (2015); \& Al Eissa \& Almuneef, (2010) stated that 
physical abuse was the most common type, followed neglect, emotional abuse and sexual abuse. This result disagreed with the result of Eissa et al., (2015) who stated that emotional abuse was the most common type followed by physical, neglect then sexual abuse.

The current study findings revealed that less than half of the studied children were exposed to high level of physical abuse. From the researcher point of view, in Egyptian society, all older family members had the right to beat children as a form of punishment and care such treatment makes children more obedient and respectful from their point of view.

Panel-Grace et al., (2018) \& Akmatov, (2011) who showed that less than half of children exposed to physical abuse .On the other hand, this result disagreed with the result of Iffland et al., (2013); \& Almadani et al, (2012) who reported that lower rate of physical abuse that about one tenth of the studied students exposed to physical abuse.

Regarding to prevalence of emotional abuse among the studied children from their family, the current study revealed that the studied children were exposed to moderate form of emotional abuse from their family. This result agreed with the result of Theoklitou et al., (2012) who showed that less than half of studied students exposed to emotional abuse. On the other hand, Şahbal et al., (2016) showed that more than half of studied students exposed to emotional abuse. Also, Ibrahim and Abou El Wafa, (2015) who reported that a higher rate of emotional abuse that the majority of the studied students had been exposed to emotional abuse from their family but another study conducted by Chen $\&$ Wei, (2011) who reported lower rate of emotional abuse that about one tenth of the studied students had been exposed to emotional abuse from their family. From the researcher point of view, the differences in prevalence of emotional abuse may be attributed to differences in socioeconomic levels and cultural differences in the way of punishment from country to country and the presence of awareness among children to report abuse, in addition to the application of the child protection laws in developed countries.

Concerning to prevalence of neglect among the studied children from their family, the current study revealed that less than half of the studied students reported moderate form of neglect. This result parallel with the result of Hospital-Based Child Maltreatment Registry, (2012); \& Al Eissa and Almuneef, (2010) who reported that less than half of the studied students exposed to neglect. On the other hand, Mennen et al., (2011); \& Sedlak et al., (2010) reported that a higher rate of neglect less than three quarter of the studied students had been exposed to neglect from their family. Also, DeVooght et al., (2011); \& Al-Mahroos, (2007) reported that lower rate of neglect less than one fifth of the studied students had been exposed to neglect from their family. From the researcher point of view, the differences in prevalence of neglect may be attributed to differences in socioeconomic levels and cultural differences in the way of punishment from country to country and the presence of awareness among children to report neglect, in addition to the application of the child protection laws in developed countries.

Regarding to prevalence of sexual abuse, the current study showed that level of sexual abuse from their family. This result was congruent with the result of Saad et al., (2016); \& Iffland et al., (2013) who showed that the minority of the studied students exposed to sexual abuse from their family. Meanwhile, the result disagreed with the result of Almadani et al, (2012) who reported that a higher rate of sexual abuse among the studied students from their family. From the researcher point of view, the differences in prevalence of child sexual abuse may be attributed to differences in socioeconomic levels, religion and cultural differences from country to country and the presence of awareness among children to report sexual abuse. 
Regarding to total level of child abuse among the studied children from their family, the current study revealed that less than half of the studied children have moderate level of child abuse. From the researcher point of view, it may be due to the Egyptian community, the moderate forms of child abuse are common and used by parents, the severe forms as burning or beating that lead to fractures are rarely found and even present, these cases aren't usually documented as parents will fabricate the reason for their child injury. The Egyptian culture values child's power assertive discipline and obedience, hence, corporal maltreatment and punishment are expected to be a common practice. These results agreed with, Panel-Grace et al., (2018) who revealed that less than half of the studied children have moderate level of child abuse.

According to distribution of physical abuse among the studied children from school, the current study findings revealed that less than half of the studied children were exposed to physical abuse from school. From the researcher point of view, all older family members felt that teachers had the right to beat students and saying that it motivates them to study. Also, teachers felt that physical punishment make students more obedient and respectful. Our findings paralleled with Şahbal et al., (2016) who reported that less than half of the studied children were exposed to physical abuse from school. On the other hand, this result disagreed with Longobardi et al., (2017) who reported that more than half of the studied children exposed to physical abuse from school. Also, Ribeiro et al., (2015) reported that the majority of children were exposed to physical abuse at school.

Concerning to the prevalence of emotional abuse at school, the current study findings revealed that less than half of the studied children were exposed to emotional abuse. This result agree with the result of Fromuth et al., (2015) who reported that less than half of the studied children were exposed to emotional abuse from school. On the other hand, this result disagreed with the result of
Nearchou, (2018); Şahbal et al., (2016); \& Ribeiro et al., (2015) who reported that the majority of students were exposed to emotional abuse at school. Also, Longobardi et al., (2017); \& El Bcheraoui et al., (2012) reported that more than three quarters of the studied students had been exposed to emotional abuse at school.

Regarding to the prevalence of neglect, the current study showed that less than half of the studied children were exposed to neglect. This result disagreed with the result of Theoklitou et al., (2012) who reported that more than half of the students were exposed to neglect at school. Also, Shahrbabaki et al., (2014) reported that about one quarter of the study students exposed to neglect from school.

Regarding to the prevalence of sexual abuse, the current study findings revealed that the minority of the study participants were exposed to sexual abuse. This result parallel with the result of Koctuirk \& Yüksel, (2018); \& Mascarenhas et al., (2015) who revealed that the minority of the studied children were exposed to sexual abuse. On the other hand, Ribeiro et al., (2015) reported that about one third of the studied children were exposed to sexual abuse at school. Also, Longobardi et al., (2017) reported that about one quarter of the studied students exposed to sexual abuse at school.

Also, the current study revealed that the majority of the study sample reported higher level of exposure to neglect, followed by physical abuse, emotional abuse then sexual abuse from school. From the researcher point of view, neglect is the most common form of abuse at school may due to large number of students in classroom so it is difficult to give attention to all students. Also, physical abuse and punishment are forbidden in schools so neglect is the most common. This result agreed with the result of Theoklitou et al., (2012); \& Shahrbabaki et al., (2014) who revealed that the majority of the study sample reported neglect, followed by emotional abuse and physical abuse but Ribeiro et al., (2015) revealed that the 
majority of the study sample reported physical abuse, followed by emotional abuse then sexual abuse. Also, Longobardi et al., (2017) reported that the majority of the study sample reported emotional abuse followed by physical abuse then sexual abuse.

Regarding to distribution of the studied children regarding to level of child abuse from school, the current study revealed that less than half of the studied children have high level of child abuse. From the researcher point of view, this may due to the Egyptian culture values child's power assertive discipline and obedience, hence, corporal maltreatment and punishment are expected to be a common practice in schools. Our results agreed with the result of Sahbal et al., (2016) who reported that less than half of school children have high level of child abuse. These results are incongruent with the results of $\boldsymbol{E} \boldsymbol{l}$ Bcheraoui et al., (2009) who reported that the majority of school children have high level of child abuse.

Regarding to distribution of the studied children regarding to level of school refusal, the current study revealed that less than half of the studied children had mild level of school refusal. This result was in agreement with, Lemkin et al., (2018); \& Al-Mansoob et al., (2018) who reported that mild level of school refusal. This finding was inconsistent with previous studies Gonzálveza et al., (2018); \& Lemkin et al., (2018) who showed that less than one third of the sample had school refusal behavior. Also, Balakrishnan \& Andi, (2019) reported that the majority of students had a higher rate of school refusal behavior. From the researcher point of view, this may due to child abuse at school or parent's negligence and lack of supervision on their children, as well as having very low expectations on education, attainment and the children will not value school and eventually will refuse to go to school.

The current study findings revealed that, the majority of the studied children reported high level of "escape from aversive social and/or evaluative situations" and more than half of the studied children have high level of avoidance or stimuli provoking negative affectivity. From the researcher point of view, if students feeling upset endures for long periods, children suffering from depression or anxiety can suddenly lose their ability to take pleasure from everyday activities. In times the children can isolate themselves entirely from both friends and family. This results in a refusal of going school, attention and concentration difficulties occurring because of depression or anxiety. This result disagreed with Tekin et al., (2018) who reported that less than half of the studied children had moderate level of "escape from aversive social and/or evaluative situations" and more than the minority of the studied children have low level of "avoidance or stimuli provoking negative.

Regarding to the correlation between total school refusal and child abuse subscale, the current study showed that there is statistically significant negative correlation between total family abuse subscale and total school refusal. While, there is a highly statistically positive correlation between total school abuse subscale and total school refusal. From the researcher point of view, this may be due to if the child treated good from family member, this will decrease stress and anxiety and help the child to give, like school and its surroundings. When the child has feeling of abuse from school, this is increase stress, anxiety and depression so isolating themselves from both school and friends. These findings agreed with Nayak et al., (2018); \& Tekin et al., (2018) who reported that emotional difficulties due to child abuse make child refuse to attend school. On the other hand, these results incongruent with Maric et al., (2012) who reported that negative thoughts related to self and school such as friends, teachers, school environment, social threat, personal failure, and over generalization may results in school refusal.

Concerning the correlation between total child abuse and total school refusal subscale among the studied children, there was no statistically significant correlation between school refusal subscale and total child abuse. From the researcher point of view, there are interactional 
factors that cause school refusal, it has been found out that attachment styles, anxiety, depression, and negative thoughts are correlated with school refusal not only child abuse from family or school. These results agreed with other studies as reported by Bahall et al., (2009); \& Christogiorgos \& Giannakopoulos, (2014).

While there was a highly statistically positive correlation between total child abuse and total school refusal. From the researcher point of view, this may due to if child has feelings of abuse from school or family members, this may increase his stress, anxiety and depression so isolating himself from both family, friends and refuse to go to school. This result was congruent with the result of Nayak et al., (2018); \& Tekin et al., (2018) who reported that emotional difficulties due to child abuse make him refuse to attend school.

\section{Conclusion}

\section{Based on the results of this study, the} following conclusions were.

Near to half of the studied children had moderate level of child abuse from their family and high level of child abuse from school. Three quarters of the studied students had moderate level of school refusal behavior. There was statistically negative correlation between family abuse and school refusal.

\section{Recommendation}

Based on the findings of this study, the following recommendations were suggested:-

$\checkmark$ Psycho-educational programs should be integrated as nursing intervention for students and their parents to enhance their psychological well- being.

$\checkmark$ Educate parents through parenting workshops and other sources of information about parenting skills and encourage them to begin talking to their children.

$\checkmark$ Supportive groups to help the students and their parents to overcome any psychological distress.
Assertiveness training program should be given to students to enhance their psychological well- being and reduce school refusal.

$\checkmark$ Community mental health nurse should holding training courses relating to the methods of normal parenting styles and teaching style and its importance in psychological well- being and school refusal of children.

$\checkmark$ Therapeutic guidance programs should be prepared for children who exposed to child abuse or have school refusal.

\section{References}

Abd El Aziz, M.S., Ismail, S.S., \& Ahmed, H.M. (2017). Sexual Abuse Prevention Program for School Age Children. American Journal of Nursing Science. Vol. 6, No. 1, 2017, pp. 1-10. Retrieved on 12/7/2020.

Afifi, TO., Boman, J., Fleisher, W., \& Sareen, J. (2009). The relationship between child abuse, parental divorce, and lifetime mental disorders and suicidality in a nationally representative adult sample. Available at: Science Direct Child Abuse and Neglect journal homepage: www.elsevier.com/locate/chiabuneg, V. 33. PP139-47. Retrieved on 20-7-2020.

Akmatov, MK. (2011). Child abuse in 28 developing and transitional countries--results from the Multiple Indicator Cluster Surveys. International Journal Epidemiol, V. 40. PP 219-227. Retrieved on 18-4-2020.

Al Eissa, M., \& Almuneef, M. (2010). Child abuse and neglect in Saudi Arabia: journey of recognition to implementation of national prevention strategies. Available at: Science Direct Child Abuse and Neglect journal homepage:

www.elsevier.com/locate/chiabuneg, $V .34$. PP 28-33. Retrieved on 18-4-2020. 
Al-Eissa, MA., AlBuhairan, FS., Qayad, M., Saleheen, H., \& Runyan. (2015).Determining child maltreatment incidence in Saudi Arabia using the ICAST-CH: a pilot study. Available at: Science Direct Child Abuse and Neglect journal homepage: www.elsevier.com/locate/chiabuneg, $V .42$. PP.174-182. Retrieved on 12-4-2020.

Almadani, O., Bamousa, M., Alsaif, D., Kharoshah, M., \& Alsowayigh, K. (2012). Child physical and sexual abuse in Dammam, Saudi Arabia: A descriptive caseseries analysis study. Egyptian Journal Forensic Science .V. 2. PP.33-37. Retrieved on 13-4-2020.

Al-Mahroos, FT. (2007). Child abuse and neglect in the Arab Peninsula. Saudi Med J 28: 241-248. Retrieved on 18-8-2020.

AMansoob, MAK., Masood, MSA., Al-Abid, AAM. (2018): An Attempt to Model Factors Affecting the School'sDropout Phenomenon in Yemen. International Journal of Education, Culture and Society. 2018; 3(5): 78-85. Available

at: http://www.sciencepublishinggroup.com/j/ijec s. Retrieved on 18-8-2020.

BBahali, K., Tahiroglu, AY., Avci, A., \& Seydaoglu, G. (2011).Parental psychological symptoms and familial risk factors of children and adolescents who exhibit school refusal. East. Asian Arch. Psychiatry. 2011;21:164169. Retrieved on 18-8-2020.

Ba- Saddik, A., \& Hattab, A.S. (2012). Emotional Abuse Towards Children by School teachers in Aden Governorate, Yemen: A Cross-Sectional Study. Available in BMC Public Health 12(1):647.

Balakrishnan, U.D., \& Andi, H.K. (2019). School Refusal Behaviour in Primary School Students: A Demographic Analysis. Journal of Asian Research. Vol. 3, No. 1, 2019. Retrieved on 15/7/2020.

Byambaa, M., Butchart, A., Norman, RE., \& Scott, J. (2012). The Long-Term Health
Consequences of Child Physical Abuse, Emotional Abuse, and Neglect: A Systematic Review and Meta-Analysis. PLoS Med 9: e1001349.Pages 49-61. Retrieved on 13/7/2020.

children by schoolteachers in Aden Governorate, Yemen: A cross-

Christoffersen, MN., Armour, C., Lasgaard, M., Andersen, TE., \& Elklit, A. (2013). The prevalence of four types of childhood maltreatment in Denmark. Clin Pract Epid Mental Health. V. 9. PP.149-56. Retrieved on 15-7-2020.

Christogiorgos, S., \& Giannakopoulos, G. (2014). School refusal and the parent-child relationship: A Psychodynamic perspective. Journal of Infant, Child, and Adolescent Psychotherapy, V. 13(3), PP.182-192. Retrieved on 15-7-2020.

Daigneault, I., Collin-Vézina, D., \& Hébert, M. (2013).Lessons learned from child sexual abuse research Prevalence, outcomes, and preventive strategies .Child and Adolescent Psychiatry and Mental Health. (7),1-9. Retrieved on 1/12/2018.

DeVooght, K., \& McCoy-Roth, M. (2011). Freundlich M. Young and vulnerable: children five and under experience high maltreatment rates. Child Trends: Early Childhood Highlights. V. 2(2):PP.1-20. Retrieved on 10-6-2020.

Devries, $K$ M., Child, JC., Allen, E., Walakira, E., Parkes, J., \& Naker, D. (2014). School violence, mental health, and educational performance in Uganda. Pediatrics. 133 (1): 129-37. Retrieved on 157-2020.

El Bcheraoui, C., Kouriye, H., \& Adib, SM. (2012). Physical and verbal/emotional abuse of schoolchildren, Lebanon. Retrieved on 188-2020.

El-Nagar, M. (1998). Incidence of Child Abuse among Primary School Children in Shebin El-Kom. Faculty of Nursing, 
Menofiya University. Retrieved on 25/12/2018.

Gilbert, L.K., Breiding, M.J., Merrick, M.T., Thompson, W.W., Ford, D.C., Dhingra, S.S., \& Parks, S.E. (2015). Childhood adversity and adult chronic disease: an update from ten states and the District of Columbia, 2010. American Journal of Preventive Medicine, 48(3), 345-349. Retrieved on 3-7-2020.

Gonzálvez, C., Vicent, M., Delgado, B., García-Fernández, J., Inglés, C., \& GómezNuñez, M. (2016). Bibliometric review of school refusal: Research perspectives and their analysis. 34(1),71-92. Retrieved on $5 / 12 / 2018$.

Gutuza, R.F., \& Mapolisa, T. (2015). Prevalence of child abuse in five primary schools in Nyanga district. Retrieved on $13 / 7 / 2020$

Hospital Based Child Maltreatment Registry. (2012). The Annual Report Council of Health Services. Saudi Arabia. Retrieved on 13/7/2020.

Ibrahim, S., \& Abou El Wafa, H. (2015). A comparative study of child abuse in children with disruptive behavior disorders of different socioeconomic classes. Volume: 36| Issue : 3 | Page : 132-138. Egypt J Psychiatry. Retrieved on 13/7/2020.

Iffland, B., Brähler, E., Neuner, F., Häuser, W., \& Glaesmer, H. (2013). Frequency of child maltreatment in a representative sample of the German population. BMC Public Health 13: 980. Retrieved on 13/7/2020.

Jordan, K., MacKay, P., \& Woods, S. (2016). Child maltreatment: Optimizing recognition and reporting by school nurses. NASN School Nurse, 32(3), 192-199. Retrieved on 13/7/2020.

Kearney, C. (2002). Identifying the function of school refusal behavior: A revision of the School Refusal Assessment Scale. Journal of Psychopathology and Behavioral Assessment. 24(4),235-45. Retrieved on 1/1/2019.
Kearney, C. A., \& Bates, M. (2005). Addressing school refusal behavior: Suggestions for frontline professionals. Children \& Schools, 27(4), 207-216.

Kearney, C. A., \& Spear, M. (2014).School refusal behavior. In L. Grossman, \& S. Walfish (Eds.), Translating Psychological research into practice (pp. 83-85). Washington, DC: American Psychological Association. Retrieved on 13/7/2020.

Koçtürk, N., \& Yüksel,F. (2018).The Characteristics of Child Sexual Abuse in the School Environment in Turkey. Journal of Child Sexual Abuse 27(1):1-18. Retrieved on 13/7/2020.

Lemkin, A., Caroline, J., Kistina, H J., Cabralb, A., \& Megan, B. (2018). School connectedness and high school graduation among maltreated youth. Available at Science Direct Child Abuse \& Neglect journal homepage:

www.elsevier.com/locate/chiabuneg, V.75. PP. 130-138. Retrieved on 18-4-2020.

Lemkin, A., Caroline, J., Kistina, H J., Cabralb, A., \& Megan, B. (2018). School connectedness and high school graduation among maltreated youth. Available at Science Direct Child Abuse \& Neglect journal homepage:

www.elsevier.com/locate/chiabuneg, V.75. PP. 130-138. Retrieved on 18-4-2020.

Longobardi, C L E., Prino, AF., \& Michele, $S$. (2017). Violence in school: An investigation of physical, psychological, and sexual victimization reported by Italian adolescents. Retrieved on 15-7-2020.

Mahram, MD., Hosseinkhani, MSc., Nedjat, MD., \& Aflatouni, MSc. (2013).Epidemiologic Evaluation of Child Abuse and Neglect in School-Aged Children of Qazvin Province, Iran J Pediatr. (2) 159164. Retrieved on 13/7/2020.

Maric, M., Heyne, D. A., MacKinnon, D. P., Widenfelt, B. M., \&Westenberg, P. M. 
(2013). Cognitive mediation of cognitivebehavioural therapy outcomes for anxietybased school refusal. Behavioural and Cognitive Psychotherapy. Retrieved on $13 / 6 / 2020$.

Mascarenhas, M.D., Malta, D.C., Lima, C.M., \& Alves da Silva. (2015). Prevalence of sexual violence and associated factors among primary school students in Brazil. Retrieved on 13/7/2020.

Matar, H.L. (2014). Identification of child physical and emotional abuse among primary school children at Menoufia governorate. Retrieved on 13/7/2020.

Maynard, B. R. Heyne, D., Brendel, K. E., Bulanda, J. J., Thompson, A. M., \& Pigott, T. D. (2015). Treatment for School Refusal Among Children and Adolescents". Research on Social Work Practice. 28 (1): 56-67. doi:10.1177/1049731515598619. ISSN 10497315. Retrieved on $4 / 122019$.

McLeod, S. A. (2018): Erik Erikson's stages of psychosocial development. Simply Psychology.

https://www.simplypsychology.org/ErikErikson.html. Retrieved on 11/11/ 2019.

Mogaddam, M., Merdad, L., Alamoudi, N., Meligy, OE., \& El-Derwi, D. (2015). Prevalence of Child Abuse in Saudi Arabia from 2000-2015: A Review of Literature. J Oral Hyg Health 3:189. Retrieved on $13 / 7 / 2020$.

Mohamed, F., Alganady, M., Mohamed, H., Thabet, R., \& Zaki, N . (2016). Relationship between Domestic Violence and Self-Esteem of School Age Children in Assiut City. IOSR Journal of Nursing and Health Science, Issue 3 Ver. V. PP 51-59.Retrieved on 18-5-2020.

National Association of School Nurses, (2016). Framework for $21^{\text {st }}$ century school nursing practice. NASN School Nurse, 31(1), Pp.45-53.Retrivied: June 23,12:15 am, 2020.

National Center for Injury Prevention and Control, Division of Violence Prevention, (2019): Child abuse and neglect perpetration. Risk and Protective Factors. Available at: https://www. cdc.gov/violence prevention/index.html. Retrieved on $31 / 1 /$ 2019.

National Council for Childhood and Motherhood (NCCM) and UNICEF (2015). Violence against Children in Egypt. A Quantitative Survey and Qualitative Study in Cairo, Alexandria and Assiut, NCCM and UNICEF Egypt, Cairo. Retrieved on $13 / 7 / 2020$.

Nayak, A., Sangoi, B., Nachane, H. (2018). School Refusal Behavior in Indian Children: Analysis of Clinical Profile, Psychopathology and Development of a BestFit Risk Assessment Model. Indian J. Pediatr. 85:1073-1078. Retrieved on 13/7/2020.

Nearchou, F. (2018). Resilience following emotional abuse by teachers: Insights from a cross-sectional study with Greek students. Available at: Science Direct Child Abuse and Neglect journal homepage: www.elsevier.com/locate/chiabuneg.Volume 78, Pages 96-106. Retrieved on 13/7/2020.

Nguyen, HT., Dunne, MP., Le, AV. (2009). Multiple types of child maltreatment and adolescent mental health in Viet Nam.Bull World Health Organ 88: 22-30. Retrieved on 13/7/2020.

PanelGrace, $\quad$ S. $\quad$ C., Dongdong, L.C.,Tabitha,O.F. (2018). Family profiles of maltreated children in Singapore: A latent class analysis. Retrieved on 13/8/2020.

Reid, K. (2014). Managing school attendance: Successful intervention strategies for reducing truancy. New York: NY: Routledge.

Retrieved on $1 / 2 / 2020$.

Ribeiro, IMP., Teixeira Ribeirol, ÁS., Pratesil, R., Gandolfil, L.(2015). Prevalência das várias formas de violência entre escolares (Prevalence of various forms of violence among school students). ACTA Paul Enferm. 2015;28(1):54-9. Retrieved on: 22/5/2020. 
Saad, S., Hashish, R.K., Abdel - Karim, R.I., Mohammed, G.F. (2016). Emotional, physical and sexual abuse and its psychological impact in children. Available at: International Journal of Contemporary Pediatrics.Aug;3(3):760-767

http://www.ijpediatrics.com. Retrieved on $11 / 8 / 2020$.

Saad, S., Hashish, R.K., Abdel - Karim, R.I., Mohammed, G.F. (2016). Emotional, physical and sexual abuse and its psychological impact in children. Available at: International Journal of Contemporary Pediatrics.Aug;3(3):760-767

http://www.ijpediatrics.com. Retrieved on 11/8/2020.

Şahbal ,ARAS., Sema, ÖZAN., \& Oya, KASAPCI. (2016). Exposure of Students to Emotional and Physical Violence in the School Environment. Noro Psikiyatr Ars, 2016 DEC: 53 (4); 303-310. Retrieved on 11/8/2020.

Sedlak, AJ., Mettenburg, J., Basena, M., Petta, I., McPherson, K. (2010). Fourth National Incidence Study of Child Abuse and Neglect (NIS-4): Report to Congress. Washington, DC: U.S. Department of Health and Human Services, Administration for Children and Families. Retrieved on 13/7/2020.

Shahrbabaki, M., Haghdoost, A., Sabzevari, L., \& Kalantari, M. (2014). Prevalence of child abuse in 15-17 year old students. Zahedan Journal Res Med Sci (ZJRMS); V.16(5): PP.11-15. Retrieved on 3-7-2020.

Tekin, I., Erden, S., Şirin Ayva, A. B., \& Büyüköksüz, $\boldsymbol{E}$. (2018). The predictors of school refusal: Depression, anxiety, cognitive distortion and attachment. Journal of Human Sciences, 15(3), 1519-1529. Retrieved on 13/7/2020.

Thambirajah, S.M. (2008). Understanding school refusal : a handbook for professionals in education, health and social care. Grandison, Karen J., De-Hayes, Louise.
London: Jessica Kingsley

Publishers. Retrieved on 11/8/2020.

Theoklitou, D., Kabitsis, N., Kabitsi, A. (2012). Physical and emotional abuse of primary. Retrieved on 13/7/2020.

Wimmer, M. (2012). "School refusal: Information for educators" (PDF). National Association of School Psychologists. Retrieved on 13/6/2020.

World Health Organization, (WHO) (2019). Preventing child maltreatment: Seven strategies for Ending Violence Against Children: A guide to taking action and generating evidence. Geneva: World Health Organization; 2019.

World Health Organization, (WHO) (2017). Preventing child maltreatment: A guide to taking action and generating evidence. Geneva, Switzerland: World Health Organization. International Journal of Contemporary Pediatrics Saad $\mathrm{S}$ et al. 3(3),760-67. Retrieved on 19/12/2018.

Wu, X., Liu, F., Cai, H., Huang, L., Li, Y., Mo, Z., \& Lin, J. (2013). Cognitive behaviour therapy combined Fluoxetine treatment superior to cognitive behaviour therapy alone for school refusal. International Journal of Pharmacology,9, 197-203. Retrieved on 13/7/2020. 
مدى الإرتباط بين إساءة معاملة الأطفال والرفض المدرسى بين طلبة المدارس الإبتائية فى مدينة بنها

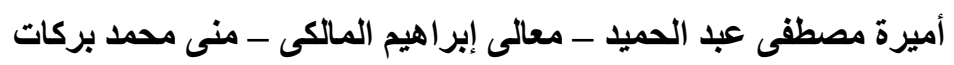

تُعرف إساءة معاملة الطفل على أنها إرتكاب أب فعل يمكن أن يلحق الضرر أو التهديد للطفل ونتيجة لللك تزيد مخاطر تعرّضهم لمشاكل صحية و سلوكية وجسدية ونفسية, وأيضا تغييرات في الأداء

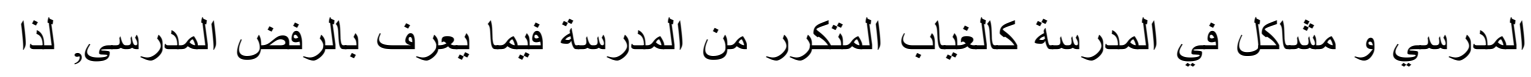

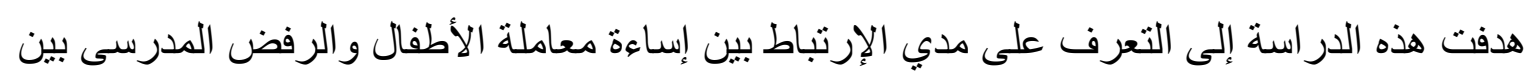

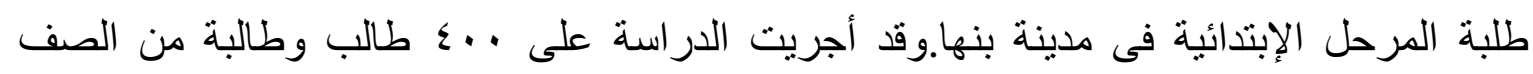

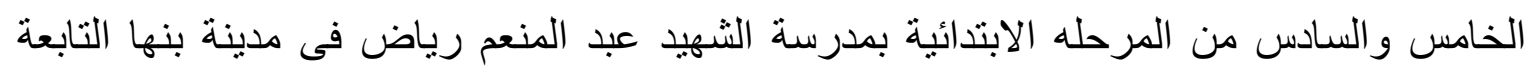

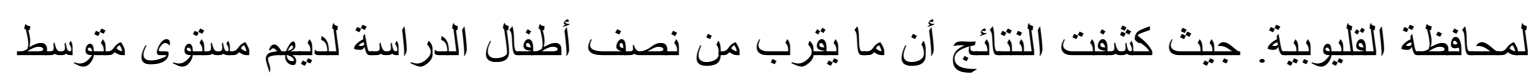

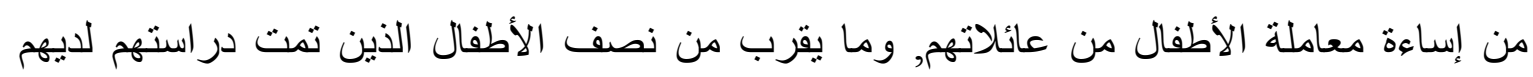

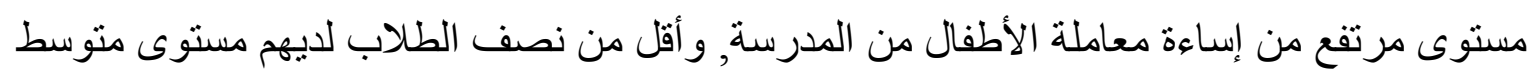
من سلوك الرفض المدرسى و كان هناك ارتباط إيجابي ذات دلالة إحصائيه بين الإساءة الكلية للطلبة

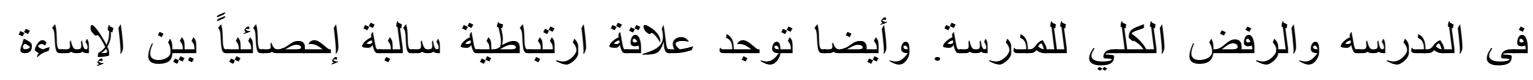

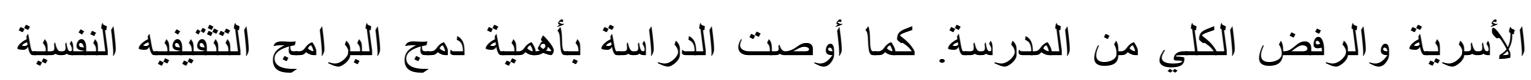

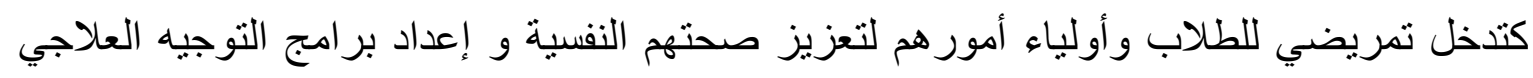
للأطفال الذين تعرضو الإساءة معاملة أو رفضوا الدر اسة. 